\title{
NUEVOS ENFOQUES EN GESTIÓN TURÍSTICA: EL PROGRAMA DE AGRUPACIONES EMPRESARIALES INNOVADORAS EN ESPAÑA ${ }^{1}$
}

\author{
Josep A. Ivars Baidal \\ Isabel Rodríguez Sánchez \\ J. Fernando Vera Rebollo \\ Alejandro Acebal \\ Instituto Universitario de Investigaciones Turísticas. Universidad de Alicante \\ josep.ivars@ua.es, isabel.rodriguez@ua.es, JF.Vera@ua.es, alejandro.acebal@ua.es
}

\section{RESUMEN}

Este estudio se enmarca en el análisis de las nuevas políticas de innovación aplicadas al turismo en España. El objetivo fundamental es evaluar la política reciente de apoyo a la creación y consolidación de Agrupaciones Empresariales Innovadoras en el ámbito del turismo, el Programa AEIs, atendiendo a su singularidad, las características de las AEIs resultantes y la valoración de sus responsables. El análisis ofrece luces y sombras y concluye con argumentos para repensar este tipo de políticas, así como con elementos de discusión interesantes en torno a la innovación derivada de los procesos de colaboración en turismo.

Palabras clave: Políticas de innovación en turismo; evaluación de políticas, Agrupaciones Empresariales Innovadoras; procesos de colaboración.

\section{ABSTRACT}

This study aims to evaluate recent tourism innovation policies in Spain, specifically those that support the creation and consolidation of the Innovative Business Group (AEI, for its

Fecha de recepción: noviembre 2012.

Fecha de aceptación: octubre 2013.

1 El presente trabajo se enmarca en el proyecto de investigación «Metodología, criterios y aplicaciones para la configuración de clusters en áreas turísticas consolidadas: innovación, complementariedad y competitividad territorial» (CSO2011-26396), financiado por el Plan Nacional de I+D+i del Ministerio de Economía y Competitividad.

Es IP del mismo es el Dr. J. Fernando Vera Rebollo. 
initials in Spanish) Programme in Tourism, its singularity, the characteristics of the resulting AEIs and the evaluation made by managers. The analysis shows the lights and shadows of the Programme and also suggests the need to reformulate these types of policies. It also highlights interesting discussion points about the innovation derived from collaborative processes in tourism.

Key words: Tourism innovation policies; policy evaluation; Innovative Business Group Programme; collaborative process.

\section{INTRODUCCIÓN}

Desde el surgimiento del turismo de masas, en la segunda mitad del s. XX, la actividad turística ha mostrado un enorme dinamismo hasta convertirse en una actividad económica y social de primer orden que ha alcanzado 1.035 millones de llegadas internacionales en 2012 y que, en 2011, ya generó el récord de más de un billón de dólares en concepto de ingresos internacionales por turismo (UNWTO, 2012). La importancia de esta actividad global contrasta, sin embargo, con el papel marginal asignado tradicionalmente a la innovación en el turismo. La capacidad de innovación del sector turístico se enfrenta a una serie de barreras constatadas en diversas investigaciones (Cooper, 2006; Hall y Williams, 2008; Hjalager, 2002; Jacob et al., 2003; Nordin, 2003): predominio de pequeñas y medianas empresas; deficiente cualificación de los recursos humanos; resistencia empresarial al cambio; baja productividad del sector; débil capacidad inversora y de acceso a financiación; limitada cooperación interempresarial y público-privada; desconexión con respecto a las actividades de I+D+i; estacionalidad; o dificultades en la transmisión y adopción del conocimiento.

Sin embargo, estas barreras no pueden generalizarse y requieren matizaciones en cada ámbito territorial y sectorial (alojamiento, restauración, transporte, etc.), a la vez que varían de acuerdo con la política y el modelo de desarrollo turístico o el papel del turismo en el sistema de ciencia e innovación, entre otros factores. Dichas matizaciones provocan un creciente debate acerca de si el turismo presenta tasas de innovación menores que otros sectores de actividad (Hall, 2009), un comportamiento diferenciado difícil de determinar porque los actuales sistemas de medición de la innovación, más propios de los sectores industriales, quizá subestiman la innovación que realmente se está produciendo en el sector turístico (Camisón y Monfort, 2012).

En cualquier caso, la innovación constituye una fuente de ventaja competitiva para las empresas y los destinos turísticos (Hjalager, 2000; Hong, 2008; Ritchie \& Crouch, 2003) $\mathrm{y}$, por consiguiente, adquiere una importancia creciente en la política turística que tiende a modificar la situación acertadamente descrita por Hall (2009), caracterizada por una escasa representación del turismo en las políticas de innovación nacionales y de la innovación en las políticas de turismo. Una situación que está cambiando en países como España mediante la configuración de una política turística que progresivamente concede mayor importancia a la innovación para la mejora de la competitividad turística.

El Programa de Agrupaciones Empresariales Innovadoras se enmarca en las nuevas iniciativas de fomento de la innovación que persigue la política turística española. Con carácter previo al análisis de este Programa se sintetiza, en primer lugar, la evolución del papel de la 
innovación en la política turística y, en segundo lugar, se revisa la aplicación del concepto cluster y de las políticas asociadas a este concepto, en el turismo, en la medida en que los principios inspiradores del Programa AEIs asimilan las agrupaciones innovadoras a clusters. No obstante, dicha identificación presenta peculiaridades que ponen de relieve la singularidad del Programa y la ambigüedad del concepto y las políticas cluster, tanto con carácter general como aplicadas al turismo. A continuación, el análisis del Programa se estructura en tres partes: la identificación de sus rasgos distintivos; la caracterización de las AEIs resultantes; y la percepción de los gestores de las AEIs. El contraste de las teorías cluster con el análisis del Programa, sirve de base para un apartado de discusión sobre aspectos esenciales de la aplicación de dichas políticas al ámbito del turismo.

\section{LAS POLÍTICAS DE INNOVACIÓN EN TURISMO}

La evaluación de políticas se considera insuficiente en la investigación acerca de la innovación en turismo (Hjalager, 2010). Indudablemente, las políticas de fomento de la innovación en esta actividad son recientes, sin embargo, es conveniente adoptar una perspectiva histórica que ayude a comprender el papel de la innovación en la política turística y su encaje actual. Este análisis diacrónico se plantea a partir de la revisión sintética de los instrumentos de planificación turística a diferentes escalas. El marco teórico se completa con la revisión de los trabajos acerca de la aplicación del concepto y las políticas cluster al turismo.

\subsection{La innovación en la política turística española}

A partir de los años sesenta, la evolución de la política turística española ha estado marcada, básicamente, por los cambios en la organización político-administrativa del país, la propia evolución de la actividad turística y el papel otorgado al turismo en las políticas públicas de las diferentes Administraciones intervinientes (Administración General de Estado, Comunidades Autónomas y Municipios). En esta política sectorial han primado los aspectos promocionales, dirigidos a la captación de demanda, y los normativos, orientados fundamentalmente a reglamentar las empresas y las actividades turísticas. Sólo recientemente se ha incorporado la innovación como uno de los ejes de la política turística.

En los años del boom turístico español, desde finales de los cincuenta a mediados de los setenta, las medidas regulatorias y de incentivo a la inversión turística coexisten con una excesiva permisividad, sobre todo en el plano territorial y medioambiental. La descentralización político-administrativa, derivada de la Constitución de 1978, supone la progresiva emergencia de las políticas regionales de turismo. Aunque los primeros planes regionales favorecen nuevos enfoques (modernización de los establecimientos, diversificación de la oferta, desestacionalización, etc.), el énfasis de la política turística continúa centrándose en la promoción.

La crisis de las llegadas e ingresos por turismo internacional a finales de los ochenta y principios de los noventa conlleva una reacción basada en medidas para fortalecer la posición competitiva española y mejorar el balance económico y social del turismo. Estas medidas, sintetizadas en el Libro Blanco del Turismo Español (1990), que contiene un análisis estratégico-competencial del turismo basado en los trabajos de Porter (1986), sientan las bases 
para superar el desajuste estructural entre la oferta española y la evolución de la demanda turística, objetivo básico de los Planes Futures de la década de los noventa (Plan Futures I y II -1992-1999).

En el Libro Blanco, la innovación se vincula con la tecnología, valorándose las dotaciones tecnológicas de las empresas turísticas por debajo de las observadas en otros subsectores industriales o de servicios, como la banca o los seguros. A partir de este diagnóstico, se propone un proceso de desarrollo tecnológico con una orientación empresarial en el que se considera fundamental la formación de los recursos humanos.

En el Plan Futures I (1992-1995) la innovación se encuadra en un Programa denominado de «Modernización e Innovación Turística» que se concreta fundamentalmente en incentivos a empresas, donde predominan claramente las iniciativas de modernización. En el Plan Futures II (1996-1999), se incluye un programa de tecnificación e innovación destinado a empresas, con especial atención a las tecnologías de la información. Asimismo, se refuerza el programa destinado al desarrollo de nuevos productos para promover la diversificación y la desestacionalización de la oferta turística española, proceso que se verá favorecido por las políticas turísticas regionales y locales.

A partir del 2000, el Plan Integral de Calidad del Turismo Español (PICTE, 2000-2006) se orienta a consolidar la posición de liderazgo del turismo español en un entorno de convergencia con Europa e introducción del euro que hace desaconsejable la competencia vía precio y justifica el énfasis del plan en la calidad de la oferta turística. Este Plan comprende un programa de innovación más sofisticado, aunque con un sesgo tecnológico que incluye tecnologías de la información, de la calidad o medioambientales.

La evolución de la estrategia basada en la calidad conduce a un nuevo enfoque de la política turística en el Plan del Turismo Español Horizonte 2020, con vigencia de 2008 a 2012, donde la innovación constituye un eje central, al menos desde el punto de vista teórico. Este Plan aboga por una nueva economía turística donde la innovación (mediante un modelo de innovación horizontal), el conocimiento (con la creación de un sistema de inteligencia turística) y la captación y el desarrollo de talento (a través de la formación y un mayor reconocimiento social de las profesiones turísticas) constituyen aspectos fundamentales. La innovación y el conocimiento se convierten, por tanto, en los fundamentos de la nueva estrategia turística, si bien el grueso de la inversión turística continúa destinándose a actividades tradicionales como la promoción, aunque, teóricamente, mejor dirigidas por la progresiva configuración de un sistema de inteligencia turística más avanzado.

En el marco de este Plan, la Administración turística española decide impulsar la participación del sector turístico en el Programa de Agrupaciones Empresariales Innovadoras (AEIs), un instrumento de política industrial para la promoción de la innovación y competitividad en el ámbito empresarial. Aunque no se trata de un instrumento de política propiamente turística (tiene cabida cualquier sector industrial) lo novedoso de esta iniciativa es la participación pionera del sector turístico en un programa tradicionalmente orientado a sectores industriales y el acceso a procesos colaborativos novedosos propios de una política cluster.

En un contexto de crisis económica y ajuste presupuestario, se elabora el Plan Nacional e Integral de Turismo (PNIT, 2012-2015). El turismo se considera un eje estratégico para la recuperación económica pero la capacidad de gasto de la Administración Pública se halla considerablemente mermada. En la fundamentación del Plan pierde cierto protagonismo 
la innovación pero se mantienen como referencias esenciales el conocimiento y el talento, siempre vinculados a la formación, con un papel destacado de la emprendeduría, que se promueve mediante líneas de crédito específicas. La innovación destaca en dos planos: relacionada con los programas para emprendedores y con el desarrollo de destinos turísticos inteligentes a partir del concepto de Smart City. En el PNIT no se encuentra referencia alguna a las Agrupaciones Empresariales Innovadoras, aunque las convocatorias de ayudas se mantienen por parte del Ministerio de Industria, Energía y Turismo (MINETUR), con una asignación al sector turístico para la anualidad 2013 superior al año precedente.

De acuerdo, con esta evolución se configuran, a distintas escalas, sistemas de innovación turística (Anton y Duro, 2010), con carácter emergente y composición y enfoques diversos. Además de la creación de la Sociedad Estatal para la Gestión de la Innovación y las Tecnologías Turísticas (Segittur), dependiente actualmente del Ministerio de Industria, Energía y Turismo, cabe destacar, a título ilustrativo de los procesos que se desarrollan en Comunidades Autónomas, la creación del Centro de Investigación Cooperativa en Turismo del País Vasco (CICtourGUNE), que integra a diversas administraciones vascas, universidades y empresas turísticas y tecnológicas; el Centro de Innovación Turística de Andalucía (Andalucia Lab), fundación impulsada por la Consejería de Turismo y Comercio que agrupa a entidades públicas y privadas del sector turístico, incluyendo universidades y centros tecnológicos; el Instituto Valenciano de Tecnologías Turísticas, que promueve la innovación en los programas de actuación de la Agencia Valenciana del Turismo; o el Parque Científico y Tecnológico de Turismo y Ocio de Tarragona, promovido por la Universidad Rovira i Virgili con la participación de agentes públicos y privados que opera a una escala subregional.

Por otra parte, aunque este análisis sintético se centra en la política turística, se observa una mayor presencia del turismo en la política científica y tecnológica al identificarse esta actividad como un sector prioritario para el desarrollo socioeconómico en el Plan Nacional de Investigación Científica, Desarrollo e Innovación Tecnológica (2008-2011) y un sector estratégico para la economía española, a la vez que maduro y con amplio margen de mejora en el desarrollo de la innovación, en el Plan Estatal de Investigación Científica, Técnica y de Innovación (2013-2016).

\subsection{La aplicación del concepto y las políticas cluster al turismo}

El concepto cluster se vinculó durante la década de los noventa en España a las teorías acerca de la ventaja competitiva de Porter, constituyéndose en una herramienta analítica integrada en los instrumentos de planificación turística. Es el caso del País Vasco (Monitor Company, 1991) y Cataluña (Monitor Company, 1992) en España; Portugal (Monitor Company, 1994); o, más recientemente, Sudáfrica (The Cluster Consortium, 1999) o Australia (Kelly et al. 2001). La referencia para estos planes es el concepto de cluster de Porter (1990; 1998) quien lo define como un grupo de empresas interconectadas e instituciones relacionadas en un determinado campo, que se encuentran próximas geográficamente, y que están vinculadas por elementos comunes y complementariedades, empresas que compiten pero también cooperan.

Más recientemente, el enfoque cluster se vincula a las políticas de innovación en turismo, tanto desde la óptica de la gestión de destinos como de iniciativas públicas a diferentes escalas (nacional o regional) que tratan de impulsar la configuración de clusters 
como vía para la innovación turística, planteamiento en que se inscribe el Programa AEIs. La investigación en torno a la aplicación del concepto cluster en turismo presenta diferentes enfoques, desde la comprensión de las dinámicas propias de un cluster turístico, su delimitación espacial y los factores que lo han conformado, a las políticas que promueven su formación como modelo de innovación.

Los trabajos acerca de las dinámicas propias de los clusters turísticos contrastan la validez de la teoría y su adaptación a las peculiaridades de los espacios turísticos a partir de estudios de caso sobre destinos específicos, con un énfasis especial en su aportación a la competitividad y al desarrollo local y regional. Jackson y Murphy (2002) aplican el concepto de cluster a destinos ubicados en Canada y Australia como herramienta analítica complementaria del concepto de distrito industrial utilizado por Hjalager (2000), e identifican las características propias de los clusters turísticos, contrastándolas con las que se asocian a los distritos industriales.

Las teorías de la aglomeración y el concepto de distrito se han aplicado fundamentalmente a espacios industriales aunque diversos autores los han utilizado como referencia para el análisis y la formulación de nuevas propuestas en torno a los sistemas turísticos locales (Aurioles et al. 2008; Debbage y Ioannides, 2004; Hjalager, 2000; Lazzeretti and Petrillo, 2006; Prats et al., 2008). Generalmente, la ubicación en un distrito se asocia a una mayor capacidad innovadora de las empresas (Garofoli, 1989; Becattini, 2005). Tal como indica Méndez (2008), la aglomeración empresarial genera una acumulación localizada de conocimiento que favorece procesos de aprendizaje colectivo que se traducen en una mayor tasa de innovación local. Aunque el concepto de distrito industrial y los clusters presentan paralelismos, el cluster porteriano encaja mejor con la heterogeneidad de empresas turísticas que operan en el complejo sistema del destino, a la vez que no está tan vinculado a los procesos clásicos de integración vertical de la cadena de valor industrial (Hjalager, 2000).

Por lo general, los trabajos acerca de los clusters incorporan siempre aspectos relativos a la competitividad. Desde esta óptica Iordache et al. (2010) analizan la aportación del turismo al desarrollo regional a partir de las ventajas competitivas que aportan los clusters como fórmula de organización que debe ser fomentada por las políticas públicas. Michael $(2003$; 2007) aborda la formación de clusters desde una escala micro, acuñando el término microcluster, en un intento de demostrar que supone una estrategia válida para una política de desarrollo turístico tanto en zonas rurales en evidente declive como en otros «microentornos». Cristina et al. (2010) estudian las estrategias de las empresas hoteleras del cluster de la Serra da Estrela (Portugal) y sus implicaciones para la competitividad regional.

La identificación de los clusters constituye otra línea de investigación fundamental que tiene como objetivos básicos delimitar el ámbito territorial de cada cluster y verificar un nivel de interacción suficiente para diferenciar un cluster de una simple aglomeración de empresas. Esta línea comprende, por tanto, métodos cuantitativos y cualitativos. Santos et al. (2008) critican la escasez de estudios centrados en probar la verdadera existencia de un cluster, circunstancia que conlleva un abuso e inapropiado uso de este concepto, y defienden la necesidad de aplicar una metodología más rigurosa que combine técnicas cuantitativas (coeficientes e índices de localización, matrices input-output, etc.) y cualitativas (entrevistas en profundidad, análisis de redes, etc.), orientadas a medir dos factores esenciales: aglomeración e interacción. 
El creciente reconocimiento de la innovación en las políticas turísticas nacionales ha renovado el interés por la teoría de los clusters como modelo territorial y organizativo que favorece la innovación. Nordin (2003) realiza un completo análisis de las relaciones entre los clusters y la innovación turística, donde enfatiza la variabilidad contextual y el carácter dinámico de los clusters, tanto desde el punto de vista territorial como temporal. El análisis de experiencias internacionales evidencia que el cluster no se percibe exclusivamente como el resultado de un proceso espontáneo si no, más bien, como un objetivo que puede ser alcanzado mediante una estrategia apropiada (Svensson et al., 2005). Desde el punto de vista de la política y la gestión turística, se plantean, por tanto, procesos para el desarrollo de clusters como los analizados por Nordin (2003) en Sudáfrica o Nueva Zelanda, o el proyecto para la creación del Cluster de Turismo de Salud (Healthy Lifestyle Tourism Cluster) en el Reino Unido (Novelli et al., 2006).

Desde el punto de vista de la innovación, los trabajos presentan diferentes enfoques. Se recalca el papel del conocimiento como factor básico de la innovación, un apartado que se relaciona claramente con la existencia de redes de relaciones entre los componentes del cluster. Bathelt et al. (2004) abordan el proceso de creación de conocimiento en los clusters diferenciando las diferentes implicaciones del conocimiento derivado de la co-localización en un entorno local (local buzz) frente al conocimiento procedente del exterior (global pipelines), mientras que Erkus (2009) estudia los diferentes tipos de redes según el tamaño empresarial en diversos clusters identificados en Antalya (Turquía). Weidenfeld et al. (2010a, 2010b, 2011) aportan otra perspectiva de análisis al concluir, en su estudio acerca de las atracciones turísticas en Cornwall (Inglaterra), que la transferencia de conocimiento y la difusión de la innovación se produce en mayor medida entre agentes que ofrecen un producto similar y se encuentran distantes geográficamente.

Las redes de relaciones se han convertido en un interesante objeto de investigación en la medida en que diferencian al cluster, o al destino como sistema local, de una mera concentración de empresas e instituciones. Estas redes se hallan directamente relacionadas con la transferencia de conocimiento y la colaboración público-privada, configurándose como un elemento fundamental de la gobernanza como nuevo paradigma de la gestión de los destinos turísticos (Scott et al. 2008; Svensson et al. 2006). El análisis de redes se vincula también a la competitividad, diferenciándose dos dimensiones interrelacionadas: el grado de centralidad del cluster en el sistema turístico global, su estructura interna y su nivel de cohesión (Prats et al., 2008). Desde el punto de vista de las políticas de fomento de la innovación en turismo, Hjalager (2012) destaca que el apoyo a la creación de clusters persigue un enfoque más sistémico, distinto de las políticas tradicionales, cuyos beneficiarios suelen ser empresas, que favorece las relaciones de colaboración y se adapta mejor a la complejidad de los procesos y a la multiplicidad de actores que operan en los destinos turísticos.

Las aportaciones son numerosas e interesantes, tanto desde el punto de vista de la investigación como de la gestión turística, pero la teoría de los clusters continúa siendo objeto de crítica. El concepto de cluster adolece de cierta imprecisión, una debilidad que, paradójicamente, favorece una adaptación flexible, aunque a veces confusa, a diferentes entornos y procesos. La delimitación de los clusters constituye un problema fundamental que deriva, sin duda, de la laxitud de la visión de Porter (1998) al considerar factible la presencia de un cluster en diferentes escalas geográficas, desde una ciudad a varios países. De igual modo, 
el grado de intensidad de las relaciones entre las empresas e instituciones que configuraría un cluster depende de la perspectiva utilizada en cada investigación. Todo ello origina una amplia tipología de clusters en la que caben situaciones muy diversas que pueden comprometer la coherencia de la teoría (clusters emergentes, potenciales, consolidados o en declive, ...), aunque Porter (1998) ha admitido la variabilidad de los clusters en cuanto a tamaño, extensión y grado de desarrollo.

Por último, las críticas a la teoría cluster se extienden a las políticas que tratan de promoverlos. Hospers et al. (2008) cuestionan su eficiencia a pesar de que los gobiernos tratan de impulsarlas con el deseo de construir su propio Silicon Valley («Silicon somewhere»). Como consecuencia de la indefinición del concepto, su difícil medición y aplicación práctica y las dudas acerca de su aportación real al desarrollo regional, Martin \& Sunley (2003) revelan determinadas inconsistencias de las políticas cluster entre las que cabe destacar las siguientes: determinadas medidas de promoción de los clusters ya están contenidas en otras políticas previas; la dificultad de delimitar los clusters complica la selección de los beneficiarios de estas iniciativas; y la identificación de los clusters está condicionada por criterios políticos que no discriminan el grado de desarrollo o consolidación de los clusters en sus medidas de apoyo.

\section{METODOLOGÍA}

El objetivo fundamental de este trabajo es evaluar la política reciente de apoyo a la creación y consolidación de Agrupaciones Empresariales Innovadoras en el ámbito del turismo, con especial énfasis en la percepción de los responsables de gestión de cada AEI. El análisis de la información aportada por Segittur se ha complementado con la contenida en las páginas web y en los planes estratégicos aportados voluntariamente por cada AEI. La investigación empírica se basa en una metodología cualitativa desarrollada ad hoc para analizar la percepción de los responsables de gestión de cada AEI turística en relación con su actividad y con el Programa. Durante los meses de noviembre y diciembre de 2012 se entrevistó a los responsables gestores de 28 AEIs mediante la técnica de entrevista cualitativa telefónica a partir de un cuestionario semiestructurado.

En el momento de la investigación existían formalmente un total de 33 AEIs turísticas inscritas en el Registro Especial del MINETUR, 2 de las cuales no contaban con la trayectoria suficiente para dar respuesta a las cuestiones básicas de la investigación y 3 de ellas rehusaron ser entrevistadas por diversos motivos. La investigación tuvo lugar en un momento crítico en cuanto a la pervivencia futura de las AEIs entrevistadas ya que, tras cuatro años de trayectoria, se encontraban en la disyuntiva de renovar su inscripción en el Registro Especial de AEIs y de rehacer sus planes estratégicos, es decir, continuar o abandonar la trayectoria iniciada como clusters. El audio de las entrevistas fue registrado para su posterior transcripción y el análisis de contenido cualitativo se ha efectuado siguiendo el proceso de codificación abierta y axial (Strauss y Corbin, 1990) con apoyo del software ATLAS.ti (versión 7.0.88).

La modalidad de entrevista empleada corresponde a la estandarizada no programada (Richardson et al, 1965; Gorden, 1969; Denzin, 1970). Las entrevistas son estandarizadas por cuanto comparten el interés por los temas objeto de investigación, pero se consideran no programadas por cuanto el guión de entrevista no establece la redacción ni el orden 
concreto de las preguntas. La elección de este formato flexible de entrevista ha permitido una aproximación eficaz al fenómeno complejo de las AEIs turísticas. La complejidad de la temática objeto de estudio obedece a una serie de factores entre los que destacan: a) existencia de una elevada heterogeneidad en las características y trayectorias de las diferentes AEIs turísticas, b) algunos temas de entrevista indagan en la percepción subjetiva de los gerentes de las AEIs, aspecto que depende de su experiencia, conocimiento y vinculación profesional con estas entidades, c) existencia de escasa información sobre la actividad y funcionamiento de las AEIs turísticas y d) se incorporan a las preguntas de investigación conceptos de aplicación compleja al ámbito de la actividad turística, como son «cluster» o «innovación». El presente estudio aporta un análisis cualitativo de la interpretación del programa por parte de los responsables de su ejecución. Se trata de un estudio monográfico de este sector novedoso por la metodología seleccionada, basada en la entrevista, que difiere de la utilizada por otros informes de evaluación realizados por la Administración impulsora del Programa (MITYC, 2011a, 2011b) y que abordan desde una perspectiva global la totalidad de sectores de actividad. Los estudios de evaluación de estas políticas en los sectores industriales son más frecuentes en España (Aragón et al., 2009; Hernández et al., 2010), incluidos los estudios específicos de evaluación global del Programa AEIs desde la vertiente académica (Ybarra y Doménech, 2011; Trullén y Callejón, 2008) y son escasos para el sector turístico, que cuenta con el trabajo de Parra y Santana (2011) desde la perspectiva de los clusters como modelos de innovación.

\section{ANÁLISIS Y EVALUACIÓN DEL PROGRAMA DE AGRUPACIONES EMPRESARIALES INNO- VADORAS (AEIS) EN EL SECTOR TURÍSTICO}

Este programa de política cluster, en su aplicación al ámbito del turismo, ha demostrado tener unas características específicas que se han manifestado tanto en la implantación territorial como en la tipología resultante, aspecto que se analiza en profundidad a continuación, incorporando la percepción y valoración de los responsables gestores de estas estructuras colaborativas sobre la base de su experiencia y trayectoria en el Programa.

\subsection{Características distintivas del Programa de AEls en el sector turístico}

El Programa de Agrupaciones Empresariales Innovadoras (AEIs), impulsado por el Ministerio de Industria, Energía y Turismo (MINETUR), a través de la Secretaría General de Industria y de la PYME, se inicia en 2007 con el objetivo de potenciar la actuación conjunta de empresas, Administración y centros de investigación pertenecientes a una actividad determinada o que funcionan como un cluster. Desde el año 2000 comienza a elaborarse una política de clusters a escala nacional con la finalidad de coordinar y complementar actuaciones que ya se estaban desarrollando en regiones como el País Vasco y Cataluña, pioneras en políticas cluster a escala internacional desde los noventa (MITYC, 2011). El carácter nacional del programa amplía estas políticas a otras regiones españolas, a la vez que integra al turismo en este tipo de políticas más habituales en sectores industriales.

Una Agrupación Empresarial Innovadora (AEI) se define normativamente como «la combinación en un espacio geográfico o sector industrial concreto de empresas, centros 
de formación y unidades de investigación públicos o privados, involucrados en procesos de intercambio colaborativo, dirigidos a obtener ventajas y/o beneficios derivados de la ejecución de proyectos conjuntos de carácter innovador» (Orden reguladora de bases ITC 2691/2006, posteriormente revisada y actualizada según la Orden IET/1600/2012). El objeto de la AEI será, por tanto, alcanzar una masa crítica tal, que permita asegurar su competitividad y visibilidad internacionales. La definición aboga por una agrupación/cluster como organización que impulsa y desarrolla procesos de innovación. Desde el punto de vista territorial, no es un requisito indispensable la concentración geográfica de las empresas.

El programa contempla desde su puesta en marcha distintas líneas de apoyo a las Agrupaciones para: a) elaboración de planes estratégicos; b) financiación de estructuras de coordinación, gestión y administración de las AEIs constituidas; c) elaboración de proyectos específicos destinados a fortalecer el potencial innovador de las empresas; d) promover acciones conjuntas o proyectos consorciados entre diferentes AEI españolas o de éstas con agrupaciones o clusters en otros países de la Unión Europea (Ministerio de Industria, Energía y Turismo, 2013).

En el Registro Especial del Ministerio constan 161 AEIs, de las cuales 21 pertenecen al sector turístico, es decir, un 13\% del total (2013). En su momento de máxima participación y, tan solo un año antes, el programa llegó a contar con 33 AEIs lo que ha supuesto una disminución considerable por razones que se contemplan más adelante en este estudio. El Programa se desarrolla de forma progresiva en diferentes fases con una distribución presupuestaria por líneas de apoyo que ha condicionado significativamente los resultados obtenidos. En 2008, primer año de implantación del Programa para el sector turístico, la financiación se concentró en la única actividad posible de las AEIs: la elaboración de planes estratégicos, documentos de reflexión que permitían identificar los retos futuros y cuya valoración positiva por parte del Ministerio permitía la inscripción en el Registro Especial de AEIs así como el acceso a otras líneas de financiación dentro del propio programa. La alta dotación presupuestaria disponible para esta actividad y el alto porcentaje de propuestas dotadas con financiación (23 propuestas de las 26 presentadas) anima al sector a participar de una iniciativa hasta la fecha desconocida pero prometedora y calificada de «ilusionante» por los propios gestores en términos de posible vía de financiación.

En 2009 comienzan a financiarse los primeros proyectos y estructuras de coordinación (figura de gerencia formal) para los que se presentan numerosas propuestas. Ante esta situación, el Programa se comporta de forma más selectiva y equitativa entre las distintas líneas de apoyo. Es el año que más financiación se destina a apoyar la dotación de estructuras de gestión formales que garanticen la continuidad de las AEIs creadas. Además, en tan solo un año de andadura del programa, el sector turístico demuestra un comportamiento muy positivo en cuando a la capacidad de organización en red y la búsqueda de alianzas entre AEIs para la presentación conjunta de proyectos consorciados.

No obstante, 2009 sería el último año de financiación de planes de estratégicos, actividad que pese a seguir siendo obligatoria, se considera que debe ser asumida, sin ayuda específica, por los propios miembros de la AEI. En el año 2010 se puede afirmar que las expectativas positivas iniciales se ven truncadas por la drástica disminución de la financiación global debido a los recortes presupuestarios que impone la crisis económica. Asimismo, durante 
varios años se paraliza la financiación a estructuras de coordinación, concretamente desde 2010 a 2012, aspecto que incide de forma especialmente negativa en la pervivencia futura de muchas AEIs. No obstante, 2013 sorprende por la recuperación tanto en términos de proyectos presentados (reanimación de las AEIs que continúan) y de la dotación finalmente asignada a turismo, siempre en función de la calidad de las propuestas y del presupuesto total disponible para la totalidad de sectores integrantes del Programa. La evolución de las diferentes líneas de ayuda se sintetiza en la siguiente tabla.

Tabla 1

EVOLUCIÓN DEL PROGRAMA DE AEIS TURISTICAS (NDE PROYECTOS Y FINANCIACIÓN POR LÍNEAS DE APOYO)

\begin{tabular}{|c|c|c|c|c|c|c|c|c|c|c|c|}
\hline & \multicolumn{2}{|r|}{2008} & \multicolumn{2}{|r|}{2009} & \multicolumn{2}{|r|}{2010} & \multicolumn{2}{|r|}{2011} & \multicolumn{2}{|r|}{2012} & 2013 \\
\hline & $\mathrm{P}$ & $\mathrm{C}$ & $P$ & $\mathrm{C}$ & $\mathrm{P}$ & $\mathrm{C}$ & $\mathrm{P}$ & $\mathrm{C}$ & $P$ & $\mathrm{C}$ & \multirow{3}{*}{$*$} \\
\hline \multirow{2}{*}{$\begin{array}{l}\text { A) Elaboración } \\
\text { planes } \\
\text { estratégicos }\end{array}$} & \multirow{2}{*}{26} & 23 & \multirow[b]{2}{*}{38} & 16 & \multirow{2}{*}{$*$} & \multirow{2}{*}{$*$} & \multirow{2}{*}{$*$} & \multirow{2}{*}{$*$} & \multirow{2}{*}{$*$} & \multirow[b]{2}{*}{$\omega$} & \\
\hline & & $1.824 .889,75$ & & 323.726 & & & & & & & \\
\hline \multirow{2}{*}{$\begin{array}{l}\text { B) Estructuras de } \\
\text { coordinación y } \\
\text { gestión }\end{array}$} & \multirow{2}{*}{1} & 1 & \multirow{2}{*}{19} & 18 & \multirow{2}{*}{$*$} & \multirow{2}{*}{$*$} & \multirow{2}{*}{$*$} & \multirow{2}{*}{$*$} & \multirow{2}{*}{9} & $3 * 2$ & 4 \\
\hline & & 57.450 & & 360.000 & & & & & & 56.237 & 83.765 \\
\hline \multirow{2}{*}{$\begin{array}{l}\text { C) Actuaciones } \\
\text { específicas }\end{array}$} & \multirow{2}{*}{2} & 2 & \multirow{2}{*}{45} & 12 & \multirow{2}{*}{26} & 6 & \multirow{2}{*}{26} & 9 & \multirow{2}{*}{20} & 8 & 17 \\
\hline & & 16.227 & & $557.062,30$ & & $239.895,00$ & & 271.073 & & 288.076 & 709.869 \\
\hline \multirow{2}{*}{$\begin{array}{l}\text { D) Proyectos } \\
\text { consorciados }\end{array}$} & \multirow{2}{*}{ - } & \multirow{2}{*}{-} & \multirow{2}{*}{21} & 11 & \multirow{2}{*}{16} & 8 & \multirow{2}{*}{12} & 4 & \multirow{2}{*}{5} & 1 & 1 \\
\hline & & & & $556.757,55$ & & $257.895,82$ & & 128.499 & & 33.350 & 39.735 \\
\hline Total presentados & 29 & 26 & 123 & 49 & 42 & 14 & 38 & 13 & 34 & 14 & 22 \\
\hline Subvención total & & $1.898 .566,75$ & & $1.797 .545,85$ & & $497.790,82$ & & 399.572 & & 377.663 & 833.369 \\
\hline
\end{tabular}

Elaboración propia a partir de datos de SEGITTUR

$\mathrm{P}=$ presentados $; \mathrm{C}=$ concedidos

* Líneas sin financiación

\subsection{Especialización, financiación y distribución territorial de las AEls turísticas}

Las agrupaciones constituidas presentan gran diversidad. La tabla 2 recoge información sintética de cada AEI en la que conviene destacar dos aspectos: su especialización y nivel de financiación recibida. Si se atiende a su especialización, es posible identificar una amplia variedad tipológica de AEIs que se pueden agrupar en las siguientes categorías:

1) AEIs con una clara especialización temática en torno a un producto turístico. Se trata del grupo más numeroso (16) y resulta altamente heterogéneo. En él se incluyen AEIs constituidas con la voluntad de desarrollar nuevos productos en destinos consolidados (música electrónica en Ibiza) o en espacios de interior con menor grado de desarrollo turístico. En este último caso, se trata de productos muy vinculados al territorio y a las especificidades culturales del mismo (turismo rural y activo, enoturismo, gastronomía, turismo ecuestre, paisajes del olivo, etc.). Asimismo destacan las AEIs cuya especialización es en productos emergentes (turismo idiomático, ecoturismo, turismo termal) o con mayor grado de consolidación (estaciones náuticas, golf, etc.). 
2) AEIs con una especialización hacia las nuevas tecnologías como vía para el desarrollo de la innovación en un sector concreto (hotelería) o en cualquier eslabón de la cadena de valor turística (carácter transversal y multisectorial). También se detectan AEIs especializadas en el desarrollo tecnológico para su aplicación a la gestión empresarial, la accesibilidad o la actualización tecnológica de empresas menos avanzadas.

3) AEIs sin una marcada especialización, cuyo objetivo es innovar en su ámbito territorial de referencia y en la actividad turística que les vincula.

El análisis de la financiación recibida por cada AEI procedente del Programa en el periodo 2008-2012 permite identificar tres franjas diferenciadas. Tan sólo un número reducido de AEIs (5) ha recibido durante su trayectoria financiación superior a los $200.000 €$ (con un techo máximo de más de $350.000 €$ en un único caso). Se trata de las primeras AEIs en constituirse en un momento de óptima disponibilidad presupuestaria del programa. Hasta un total de 12 AEIs se englobarían en la franja de financiación media, por lo general, recibida de forma irregular con concentración en las primeras anualidades (realización del plan estratégico y realización de uno, máximo dos proyectos). Un cómputo de 14 AEIs ha alcanzado un nivel de financiación más bajo aunque este hecho está relacionado con una constitución posterior, a partir de 2010 y en una coyuntura de reducción presupuestaria.

Tabla 2

RELACIÓN DE AEIS SEGÚN ESPECIALIZACIÓN Y FINANCIACIÓN RECIBIDA (2008-2013)

Nombre y año de constitución $\quad$ Especialización

\begin{tabular}{|c|c|c|}
\hline & & Programa \\
\hline $\begin{array}{l}\text { Turistec, Cluster de tecnologías de la } \\
\text { información y la comunicación aplicadas al } \\
\text { turismo de les Illes Balears - } 2008\end{array}$ & $\begin{array}{l}\text { Soluciones tecnológicas a empresas del } \\
\text { sector turístico }\end{array}$ & Alta \\
\hline $\begin{array}{l}\text { Asociación Centro de Investigación } \\
\text { cooperativa en turismo Cictourgune- } 2009\end{array}$ & $\begin{array}{c}\text { Nuevas tecnologías en la gestión } \\
\text { empresarial. Innovación organizativa y en } \\
\text { marketing }\end{array}$ & Media \\
\hline $\begin{array}{l}\text { Asociación Rutas del vino y brandy del } \\
\text { marco de Jerez-2009 }\end{array}$ & $\begin{array}{l}\text { Cultura vitivinícola de la región de Jerez } \\
\text { (ruta, club de producto) }\end{array}$ & Alta \\
\hline Estaciones Náuticas-2009 & $\begin{array}{c}\text { Innovación en el concepto de Estación } \\
\text { náutica }\end{array}$ & Media \\
\hline Turismo de Navarra-2009 & $\begin{array}{c}\text { Sin especialización definida. Proyectos } \\
\text { horizontales }\end{array}$ & Media \\
\hline Turismo Rioja Alta-2009 & Enoturismo & Media \\
\hline $\begin{array}{l}\text { TURINCAL-Turismo e innovación en } \\
\text { Castilla-León-2009 }\end{array}$ & $\begin{array}{l}\text { Cultura, patrimonio y medio ambiente en el } \\
\text { medio rural }\end{array}$ & Alta \\
\hline $\begin{array}{l}\text { Federación de Empresas Innovadoras } \\
\text { Turísticas de la Provincia de Castellón-2009 }\end{array}$ & Sin especialización definida & Media \\
\hline Turismo Rural Extremadura-2009 & $\begin{array}{l}\text { Turismo rural y otros subsectores turísticos. } \\
\text { Desarrollo turístico sostenible }\end{array}$ & Media \\
\hline $\begin{array}{l}\text { Plataforma Turística Turismo de } \\
\text { Madrid-2009 }\end{array}$ & Networking para el acceso a la innovación & Alta \\
\hline Asociación el Viajero Experiencial-2009 & $\begin{array}{l}\text { Innovación basada en el concepto de } \\
\text { experiencia turística }\end{array}$ & Media \\
\hline
\end{tabular}


Nombre y año de constitución

Especialización

Financiación total recibida del

Programa

\begin{tabular}{|c|c|c|}
\hline $\begin{array}{l}\text { TURAL- Turismo Rural Castilla La } \\
\text { Mancha-2009 }\end{array}$ & Innovación en el sector del turismo rural & Baja \\
\hline $\begin{array}{l}\text { Asociación para el desarrollo del } \\
\text { Ecoturismo en Espacios Naturales } \\
\text { Protegidos-2009 }\end{array}$ & Ecoturismo en ENP & Baja \\
\hline León Innova-2009 & Restauración y gastronomía & Baja \\
\hline $\begin{array}{l}\text { Asociación para el Fomento del Turismo } \\
\text { Idiomático en España-2009 }\end{array}$ & Turismo idiomático & Media \\
\hline $\begin{array}{l}\text { ITUR Sector Turístico de la Provincia de } \\
\text { Granada-2009 }\end{array}$ & Innovación en procesos y gestión & Baja \\
\hline Andalucía Centro Turismo-2009 & Innovación tecnológica & Baja \\
\hline Ibiza Music Cluster-2009 & Música electrónica & Media \\
\hline Centro Tecnológico Nacional del Golf-2009 & Campos de golf & Media \\
\hline $\begin{array}{l}\text { AEI de Restauración, Hospedaje y Turismo } \\
\text { de Galicia-2009 }\end{array}$ & Sin especialización concreta & Media \\
\hline $\begin{array}{l}\text { Equitur Turismo Ecuestre en el } \\
\text { Guadalquivir-2009 }\end{array}$ & Turismo ecuestre & Baja \\
\hline $\begin{array}{l}\text { Turismo en Reservas de la Biosfera } \\
\text { Españolas (TUREBE)- } 2010\end{array}$ & Ecoturismo & Alta \\
\hline Innova Gran Canaria-2010 & $\begin{array}{c}\text { Sin especialización. Turismo como } \\
\text { actividad transversal }\end{array}$ & Media \\
\hline Termal de Galicia-2010 & Turismo termal & Media \\
\hline Activa y Rural-2010 & Turismo rural y turismo activo & Sin financiación \\
\hline Turismo Accesible & $\begin{array}{l}\text { Aplicación de nuevas tecnologías al turismo } \\
\text { accesible }\end{array}$ & Baja \\
\hline $\begin{array}{l}\text { Asociación Cluster Tenerife de Innovación } \\
\text { Turística }\end{array}$ & $\begin{array}{l}\text { Cluster multisector, empresas de toda la } \\
\text { cadena de valor }\end{array}$ & Baja \\
\hline $\begin{array}{l}\text { Agrupación Empresarial Innovadora } \\
\text { Instituto Tecnológico Hotelero }\end{array}$ & $\begin{array}{l}\text { Nuevas tecnologías e innovación en el } \\
\text { sector hotelero }\end{array}$ & Media \\
\hline $\begin{array}{l}\text { Asociación de Empresas Turísticas para la } \\
\text { innovación en la Comunidad Valenciana } \\
\text { (MTA CONNECT)-2010 }\end{array}$ & $\begin{array}{c}\text { Agrupación horizontal } \\
\text { Proyectos tecnológicos y formación sobre } \\
\text { las nuevas tecnologías }\end{array}$ & Media \\
\hline $\begin{array}{l}\text { Cluster de Innovación Tecnológica en } \\
\text { Turismo de les Illes Balears- } 2010\end{array}$ & $\begin{array}{c}\text { Innovación y tecnología aplicados a } \\
\text { cualquier eslabón de la cadena de valor del } \\
\text { turismo }\end{array}$ & Baja \\
\hline $\begin{array}{l}\text { AEI Sector Turístico de la Comunidad } \\
\text { Valenciana-2011 }\end{array}$ & $\begin{array}{l}\text { Sin especialización concreta. Innovación en } \\
\text { el sector turístico }\end{array}$ & Baja \\
\hline AEI de Los Paisajes del Olivo-2012 & Sector turístico vinculado al olivar & Baja \\
\hline AEI Ceuta y Melilla-2012 & Sin especialización concreta & Media \\
\hline $\begin{array}{l}\text { Asociación Cluster de Turismo de } \\
\text { Montaña-2013 }\end{array}$ & Turismo de montaña & Baja \\
\hline
\end{tabular}

Registro Especial de Agrupaciones Empresariales Innovadoras y SEGITTUR. Elaboración propia.

Financiación alta: Más de 200.000€

Financiación media: Entre $100.000 €$ y $200.000 €$

Financiación baja: Menos de $100.000 €$ 
Por lo que respecta a la distribución territorial, una de las cuestiones clave del análisis de las AEIs es la que relaciona su presencia en un área determinada con el grado de especialización turística de ese territorio y el modo en que su operatividad y objetivos están en consonancia con una base territorial específica. Si se agrupa a estas entidades según su ámbito territorial de referencia, se observa que un $21^{\prime} 8 \%$ de las AEIs se definen como de ámbito nacional (Fig.1). Son las agrupaciones relacionadas con un producto o sector determinado (estaciones náuticas, campos de golf, turismo activo, turismo accesible, áreas protegidas, turismo idiomático). Por tanto, la colaboración entre empresas se fundamenta en el mismo producto y no en el criterio de especialización territorial. Se trata de las AEIs que menos se adecúan al concepto tradicional de cluster en el que las empresas comparten proximidad geográfica. En realidad, tienen un comportamiento relacional similar al de una red ya que la proximidad física no es relevante en sus relaciones de cooperación.

En cuanto a las referidas a un ámbito territorial específico, destaca que el mayor número corresponda a regiones y áreas de interior $(34,37 \%)$, dedicadas en este caso a proyectos horizontales sin especialización definida, en ocasiones reproduciendo el papel de organizaciones empresariales. No obstante, son las que proyectan identidad de destino, como principal referencia, y se orientan a la creación de clusters de naturaleza territorial. En el caso de que incorporen especialización turística, van referidas a patrimonio, cultura, gastronomía y medio ambiente en áreas rurales, es decir los aspectos esenciales de espacios turísticos basados en este tipo de recursos. En este caso, el territorio actúa como medio que propicia el emprendimiento y la innovación ya que las PYMES al no poder desencadenar un proceso de innovación por sí mismas necesitan acudir a los recursos existentes en el territorio donde se asientan (Caravaca et al., 2002).

En el sentido opuesto, las regiones mediterráneas, como área de especialización turística, solo concentran el $15^{\prime} 6 \%$ de las AEIs, lo cual denota escasa correlación entre la creación de clusters y áreas con trayectoria y especialización turística. Además, las AEIs que funcionan en las regiones mediterráneas están dedicadas a proyectos tecnológicos y se refieren a ámbitos de especialización turística. Mayor es la presencia de AEIs en el caso de las comunidades insulares, Baleares y Canarias, puesto que suman otro $15^{\prime} 5 \%$ de agrupaciones por lo cual sí se podría establecer el correlato con el grado de especialización productiva en turismo, centradas en cuestiones tecnológicas y competitividad empresarial.

Por otra parte, las AEIs del área atlántica y cantábrica son de ámbito autonómico, como base de su identidad, y atañen a productos especializados (termalismo, gastronomía) o tecnología en el sector turístico. En apretado balance, se podría hablar de la falta de correlato entre el grado de especialización en turismo y la presencia de AEIs, salvo en el caso de las comunidades insulares, y en la presencia de un importante número de agrupaciones en regiones interiores, como forma de acometer proyectos conjuntos de dinamización turística sobre un referente territorial de identidad.

Las referencias iniciales con las que surgen las AEIs analizadas en el ámbito del turismo son, en unos casos, la cooperación interempresarial y de agentes públicos en un área geográfica determinada. En otros casos, es la colaboración en torno a un producto o sector de especialización, entre agentes privados y públicos, el argumento aglutinador para constituir una AEI, es decir el trabajo conjunto en un proyecto al margen del territorio donde se actúa. Bajo esta doble perspectiva, es posible clasificar las AEIs estudiadas de tal manera que la mitad de las agrupa- 
ciones analizadas tiene la identidad territorial como su principal referencia, ya sea una región, comarca o área de especialización productiva concreta; mientras que un 34`3\% de AEIs se han constituido sobre la base de un producto como referencia e identidad esencial de su dinámica. En el restante $15^{\prime} 6 \%$, se trata de agrupaciones que hacen de la especialización o innovación su elemento aglutinador. En estos casos, la innovación suele ser sinónimo de aplicaciones y difusión de tecnologías en el turismo, lo que explica que una buena parte de éstas se definan como orientadas a la innovación o soluciones tecnológicas, aplicadas a la gestión, organización o marketing, lo cual imprime un sesgo evidente al concepto de innovación.

Figura 1

\section{DISTRIBUCIÓN GEOGRÁFICA Y ESPECIALIZACIÓN DE LAS AEIS DE TURISMO EN ESPAÑA (2012*)}

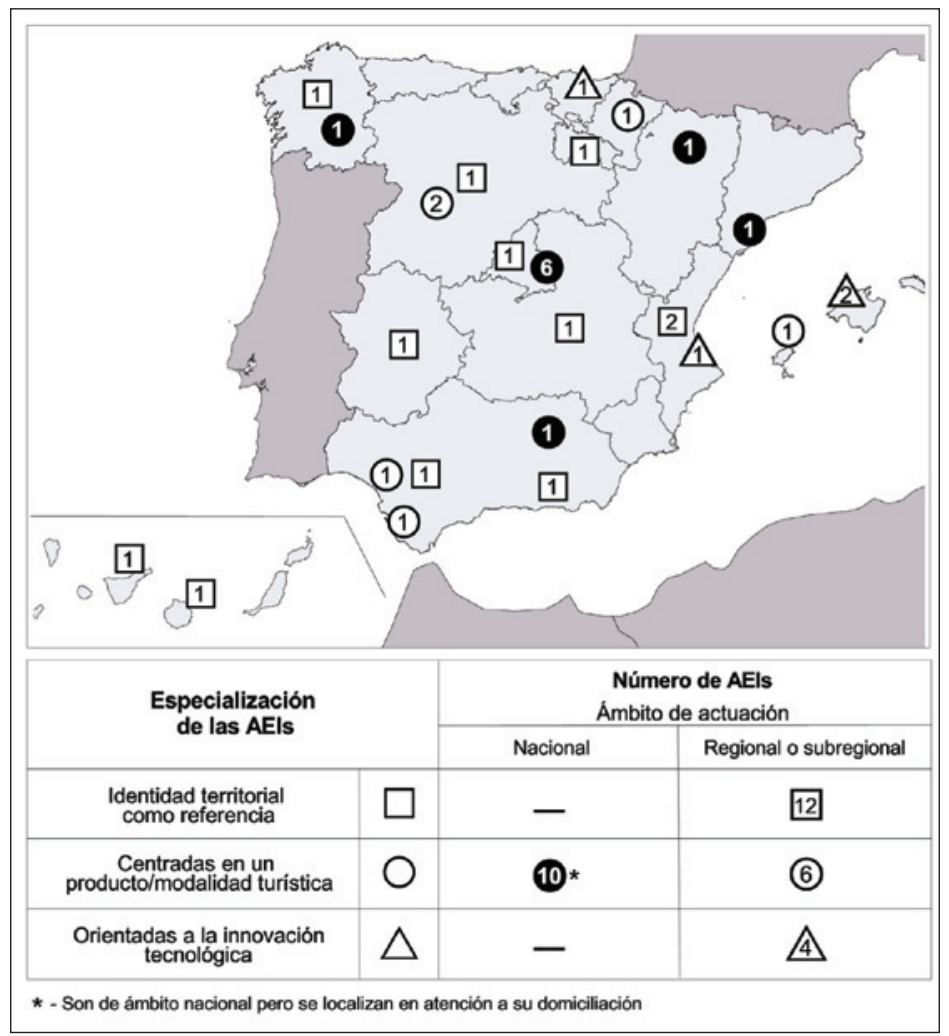

* Sobre un total de 32 AEIs existentes en 2012

Fuente: Registro Especial de Agrupaciones Empresariales Innovadoras y entrevistas realizadas. Elaboración propia.

El análisis tipológico revela claramente la escasa presencia de verdaderos clusters territoriales, sistemas localizados de empresas e instituciones a escala local o subregional, entre los que cabría identificar los destinos que cuentan con una masa crítica de oferta en diferentes entornos geográficos (litoral, urbano o rural). Frente a la innovación orientada a sistemas 
locales de empresas e instituciones, en la práctica el Programa ha beneficiado relaciones de colaboración interempresarial más convencionales, aglutinadas, básicamente, en torno a un producto común, a un subsector turístico determinado o a proveedores tecnológicos, relaciones enmarcadas en ámbitos político-administrativos y no en espacios turísticos con dinámicas funcionales diferenciadas.

\subsection{Valoración de los responsables gestores de las AEls acerca de su actividad y trayectoria en el marco del Programa}

A partir de las entrevistas en profundidad con los responsables de la gestión de las AEIs se han analizado con detalle una serie de aspectos que permiten valorar la actividad, trayectoria y perspectivas futuras de las AEIs participantes en el Programa. Dichos aspectos se agrupan en apartados relacionados con: 1) miembros integrantes y nivel de participación; 2) dinámica de las relaciones internas y externas; 3) existencia de estructuras de gestión y coordinación formales; 4) tipo de actividades desarrolladas; 5) factores favorables y limitantes en el desarrollo de la actividad; 6) evolución y retos futuros de las AEIs.

1) Miembros integrantes y nivel de participación. La normativa contempla que los solicitantes y beneficiarios de las ayudas sean tanto colectivos, agrupaciones o asociaciones sin ánimo de lucro como agencias y organismos públicos autonómicos y locales. En numerosas AEIs, los organismos públicos han jugado un papel impulsor decisivo en términos de financiación tanto en la creación como en su soporte posterior aunque su nivel de involucración y participación en la fase de desarrollo de actividades ha sido menor.

La composición de las AEIs, por subsectores turísticos, es diversa. Predominan las que integran diferentes subsectores (alojamiento y hostelería, empresas de consultoría turística y de base tecnológica) y se agrupan desde el punto de vista temático (por producto turístico, por ejemplo) o territorial. No obstante, también hay AEIs especializadas en un sector, generalmente, hotelería o restauración. La participación empresarial suele canalizarse a través de sus asociaciones, constatándose un nivel medio-bajo de empresas que se involucran a título particular en las AEIs.

La propia normativa contempla a las empresas, universidades y administraciones como miembros integrantes que deben relacionarse y de cuya interacción se espera que surja la innovación en base al modelo conocido como Triple Hélice (Etzkowitz, 2003). Sin embargo, el nivel de participación de los miembros integrantes ha sido muy dispar. Las empresas han mostrado un comportamiento más activo, especialmente las de carácter tecnológico o dedicadas a la consultoría, por su involucración más directa en el desarrollo de proyectos. Asimismo, los entrevistados han dejado constancia de la escasa involucración de universidades y centros de investigación, considerados-ajenos a las necesidades del sector empresarial.

2) Dinámica de las relaciones internas y externas. La elevada presencia de asociaciones empresariales indica la existencia de relaciones de asociacionismo previas entre los miembros que gracias al programa de AEIs se intensifican, en un primer estadio, con motivo de la elaboración conjunta de su plan estratégico y, posteriormente, con el desarrollo de los primeros proyectos innovadores identificados en dicho plan. En general, la constitución de las AEIs ha mejorado el nivel de colaboración, siendo la relación personal y la confianza aspectos determinantes a para iniciar proyectos conjuntos. Además, ha servido para reunir 
actores no habituales (universidades y centros de investigación) con el sector empresarial y público en la fase inicial de elaboración conjunta de un plan estratégico, una acción especialmente importante en sectores muy atomizados o con escasa trayectoria colaborativa (turismo idiomático, cluster musical en Ibiza, entre otros).

Los gerentes entrevistados valoran positivamente el intercambio de información y experiencias entre las diferentes AEIs, un aspecto que ha sido incentivado desde Segittur, al valorar positivamente los proyectos consorciados en las evaluaciones y promover la organización de encuentros anuales entre AEIs para compartir experiencias y generar el networking necesario para la elaboración de proyectos conjuntos. Por otra parte, desde el punto de vista de las relaciones y funcionamiento de la AEI, algunos entrevistados consideran relevante la concentración territorial de los miembros del cluster por la mayor facilidad de generar encuentros y fomentar las relaciones, aunque el programa no prioriza el «efecto aglomeración» ni existe consenso en relación a este aspecto por parte de la totalidad de entrevistados. En relación a posibles vínculos internacionales, únicamente un número reducido de AEIs ha mencionado tener experiencia en la gestión de proyectos internacionales o vínculos comerciales con empresas y organismos de otros países.

3) Existencia de estructuras de gestión y coordinación formales. Éste ha sido un aspecto de vital importancia en la trayectoria y continuidad de muchas AEIs. Contar con una gerencia asignada formalmente a la tarea de dinamizar y desarrollar las actividades contempladas por cada AEI ha supuesto una ventaja comparativa respecto a aquellas que no han podido contar con esta figura por falta de recursos internos y externos (ayudas en forma de subvención pública). Estas estructuras se contemplaban como línea de financiación específica del Programa, con una interesante dotación en 2009 (20.000 a cada AEI existente) aunque en años siguientes dejó de existir financiación para este concepto. Numerosos entrevistados han señalado que en ausencia de la figura formal de un gerente, los socios han demostrado su incapacidad para asumir las tareas de la AEI de forma voluntaria al tratarse de una actividad adicional a su dedicación normal y por falta tiempo. En ausencia de este ente tractor, el interés y participación de los socios ha disminuido progresivamente, hecho al que se ha vinculado la desaparición de numerosas AEIs.

4) Tipo de actividades desarrolladas. Las actividades se han centrado fundamentalmente en el fomento de la cooperación e interlocución entre los socios, la formación a sus miembros, la investigación vinculada al desarrollo de proyectos, la información y el asesoramiento, entre otras. Sin duda, actividades favorecedoras de un contexto más propicio a la innovación perseguida en el objetivo de constitución de estas AEIs. No obstante, la actividad con mayor repercusión en la innovación ha sido la investigación y el desarrollo de proyectos piloto. Prácticamente todos los proyectos desarrollados han tenido un componente tecnológico aunque se vinculan con todos los tipos de innovación contemplados en el Manual de Oslo (innovación en organización, proceso, productos/servicio, comercialización). Las AEIs, gracias a la financiación del Programa, han desempeñado una interesante labor de I+D, necesaria para el desarrollo de proyectos de mayor envergadura difíciles de financiar por empresas individuales. Sin embargo, el desarrollo de estos proyectos no ha culminado en una fase de comercialización y difusión como cabría esperar, siendo escaso el número de proyectos que han sido implantados -más allá de los ejercicios piloto- por los propios socios de la AEI o comercializados en un ámbito de mercado. 
5) Factores favorables y limitantes en el desarrollo de la actividad. El desempeño de las AEIs se ha visto facilitado o dificultado por una serie de factores que pueden diferenciarse entre externos e internos. Entre los factores limitantes externos, constituye un factor crítico la reducción de la dotación económica del Programa como consecuencia de los ajustes presupuestarios derivados de la crisis económica. En relación al objetivo de innovación y los factores que han dificultado su consecución, se hace alusión a la escasa tradición de vincular la innovación al turismo, la existencia de-un importante sesgo tecnológico en la concepción de la misma y una manifiesta descoordinación entre las administraciones respecto a las iniciativas de innovación turística.

Por su parte, los factores limitantes internos se vinculan a las dificultades derivadas de la obtención de financiación, tanto interna ante la escasez de medios (económicos, humanos y técnicos) como externa (ayudas públicas, co-financiación privada, etc.) dado el difícil contexto económico. Otros factores que han incidido de forma negativa en la actividad de las Agrupaciones han sido el desequilibrio existente entre el diagnóstico inicial de los planes estratégicos acerca de las necesidades de cada sector -elaborado sin una involucración real de los miembros y ambiciosos en exceso en cuanto a actuaciones y proyectos- y las actuaciones efectivamente desarrolladas en una coyuntura económica que pronto los dejó obsoletos; el déficit de cultura de cooperación entre los agentes del sector; la falta de implicación de los miembros de la AEI, que no siempre perciben de manera clara los beneficios que ésta les reporta; y la necesidad de adaptar los proyectos a sus necesidades reales.

Por el contrario, los aspectos favorables derivados de la condición de AEI se vinculan claramente con la generación de sinergias entre los miembros de la AEI a partir de objetivos comunes, el impulso inicial a la colaboración al que induce el Programa y el apoyo financiero que ha prestado así como la contribución del mismo a un proceso de reflexión estratégica en torno a la innovación turística con posibilidades de aplicación práctica. Estos aspectos positivos justifican una valoración generalmente favorable del Programa. No obstante, únicamente un tercio de los entrevistados se muestra satisfecho o muy satisfecho con el grado de cumplimiento de sus objetivos. Entre los retos que afrontan las AEIs actualmente constituidas destaca, en primer lugar, la búsqueda de financiación, pública y privada y, en segundo lugar, la necesidad de intensificar las relaciones de colaboración e incrementar la representatividad de las AEIs en el sector turístico español.

6) Evolución y retos futuros. La continuidad de las AEIs parece estar condicionada a la búsqueda de financiación externa y posibilidades de co-financiación, la elaboración de planes estratégicos más realistas y adaptados a sus necesidades, búsqueda de nuevos socios y representatividad, entre los más mencionados. Se demanda, además del apoyo financiero, un mayor nivel de exigencia por parte de los responsables del Programa a las AEIs en el cumplimiento de sus objetivos, una mejor adaptación a las necesidades del sector, acompañamiento y asesoramiento de Segittur como organismo responsable del Programa para el sector, una mejor promoción de las AEIs para incrementar su reconocimiento institucional, entre otros aspectos.

Tras cuatro años de trayectoria, la etapa de creación y puesta en marcha de las AEIs finaliza con la necesidad de realizar un balance que no para todas es positivo. En el momento de la investigación, la mayoría de AEIs se encontraban próximas a la necesidad de renovar su condición formalmente y elaborar un nuevo plan estratégico. Era, por tanto, un momento crítico en cuanto a la decisión de continuidad a corto plazo. De hecho, las cifras posteriores han evidenciado el futuro de aquellas AEIs que se encontraban en una disyuntiva de continuidad. 
Tras el estudio realizado, se identifican a continuación aquellos aspectos que demuestran ser clave para la viabilidad futura de una AEI:

- Existencia de buenas relaciones y actividades de colaboración previas entre los socios, asimilables a un cluster natural.

- Apoyo económico adicional de otras Administraciones Públicas regionales o locales.

- Estructura de gestión interna activa con figura de gerente contratado.

- Estabilidad interanual en la recepción de fondos del Programa.

- Capacidad de autofinanciación a partir del aporte de los socios y de la comercialización de los proyectos realizados.

- Mayor implicación de los asociados derivada de una mejor percepción de los beneficios de la AEI.

- Desarrollo de iniciativas más avanzadas relacionadas con la innovación.

- Presencia de socios turísticos y tecnológicos relevantes.

La figura 2 recoge los aspectos arriba mencionados y permite observar el comportamiento y la percepción diferencial de las AEIs según sus perspectivas de continuidad en diferentes apartados, desde las condiciones de creación de la AEI hasta los factores más importantes para su desarrollo.

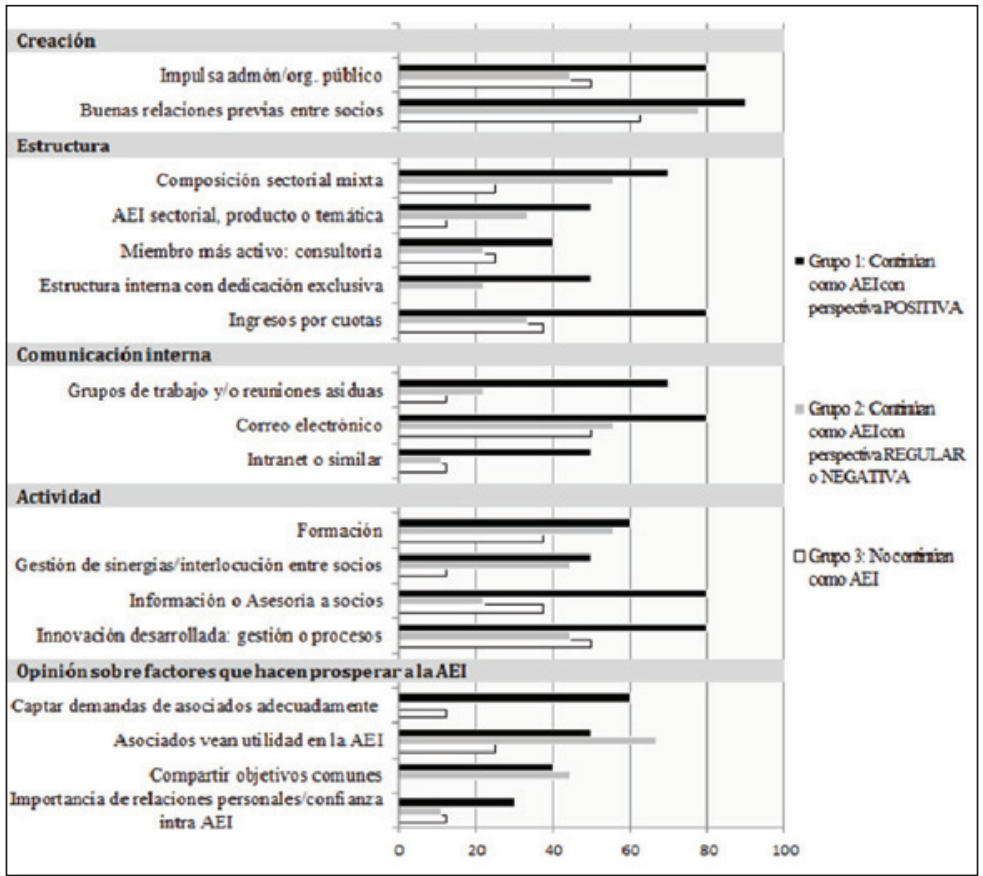

Elaboración propia

Nota: La figura expresa porcentajes a partir de las respuestas de las AEIs (Variables multirrespuesta) 


\section{DISCUSIÓN}

El Programa AEIs forma parte de una estrategia gubernamental que pretende favorecer la existencia de instrumentos más sistemáticos que faciliten la colaboración y la transferencia de conocimiento con el objetivo de eliminar las barreras que existen en torno a la innovación. El instrumento de política adopta la forma de cluster, por primera vez, llevado al ámbito del turismo en España. Inicialmente, el programa se adapta perfectamente al sector turístico, caracterizado por un sector de PYMES atomizado y con dificultades para la colaboración, situación de partida que el cluster podría corregir fomentando las relaciones empresariales, los flujos de conocimiento y una masa crítica que permita la innovación. Esta investigación, ha permitido evaluar la respuesta a este instrumento de política por parte de los agentes responsables de su desarrollo, además de contrastar los aspectos teóricos que sustentan una política cluster con la realidad de la muestra analizada, desde su especificidad turística (Tabla 3).

Uno de los aspectos clave de la teoría cluster es que la proximidad geográfica permite un mejor acceso a la información y a la existencia de un conocimiento común (Bell, 2005). Sin embargo, el estudio realizado no arroja información concluyente acerca de que la proximidad geográfica sea relevante para las relaciones de cooperación. De hecho, el estudio revela que para algunas AEIs la proximidad geográfica facilita las relaciones y los encuentros mientras para otras la globalización y la facilidad de conexión digital restan importancia al papel de la geografía en la línea que defienden algunos autores (Morgan, 2004). En cualquier caso, la proximidad geográfica por sí misma no ha sido destacada como condición necesaria o suficiente para que ambos, aprendizaje e innovación, tengan lugar, algo que también se ha observado previamente (Boschma, 2005). En el estudio realizado, se comprueba que, en ocasiones, es más relevante la «dimensión cognitiva» de la proximidad (tener una misma base de conocimiento y experiencia) así como la proximidad social (interacción basada en la afinidad, vínculos directos y confianza). Esta dimensión es la que ha imperado en la creación de alianzas entre distintas AEIs localizadas en diferentes ámbitos territoriales. La propia flexibilidad del término cluster ha facilitado su adopción a diferentes escalas espaciales (territorio nacional, regiones, destinos) y a un gran espectro de especializaciones temáticas en las que la proximidad geográfica no ha demostrado ser un elemento determinante.

La mejora de los niveles de cooperación se ha mostrado como uno de los beneficios intangibles de la pertenencia a un cluster turístico (Novelli et al., 2006), aspecto que se corrobora en este estudio, que además permite aportar información empírica adicional al respecto. En este sentido, los niveles de cooperación óptimos se han dado en aquellos clusters que ya contaban con una trayectoria de colaboración previa en torno a la creación de un producto turístico (estaciones náuticas, ruta del vino, etc.). Otros aspectos que han facilitado una cooperación más fluida han sido la existencia de una figura facilitadora como la de gerente contratado y el hecho de percibir la utilidad y beneficio de los proyectos innovadores a desarrollar. Sin embargo, no hay que olvidar que la falta de colaboración ha sido una de las principales barreras a la efectividad de este tipo de políticas (Novelli, 2006) lo que también se comprueba en la experiencia de este Programa en el sector turístico. De hecho, la falta de cooperación ha sido uno de los puntos débiles del Programa en un sector con escasa cultura colaborativa.

Por otro lado, no se ha conseguido involucrar a los entes generadores de conocimiento por excelencia como universidades y centros de investigación, incorporados únicamente 
como presencia formal y en una fase de planificación inicial. Y ello pese que la teoría sugiere que los innovadores más avanzados y las innovaciones más radicales suelen requerir mayor interacción con las universidades (Pittaway et al., 2004). Finalmente, cabe destacar que la cooperación no ha sido una dinámica constante en el tiempo sino que demostró ser mayor en el proceso de planificación conducente a la elaboración de planes estratégicos en que se involucraron más actores que posteriormente se redujo a los directamente implicados en el desarrollo de proyectos (empresas tecnológicas en colaboración con las turísticas).

En línea con estudios precedentes que cuestionan el impacto de los clusters en la innovación (Martin \& Sunley, 2001) el análisis del Programa en el sector turístico tampoco permite establecer una relación sólida y empíricamente contrastada de la asociación positiva entre pertenencia a cluster e innovación. Entre otras razones porque los proyectos de I+D desarrollados en escasas ocasiones han sido llevados a la practica en el ámbito del cluster o alcanzado un ámbito de mercado, lo que, por otro lado, ha limitado, las posibilidades de transferencia de conocimiento al sector. En este sentido, se han encontrado barreras como la falta de cultura de innovación del sector y la excesiva dependencia del estímulo público, en ausencia del cual muchas AEIs han manifestado su incapacidad para desarrollar proyectos innovadores, sin mencionar que el surgimiento de algunos de estos clusters estuvo motivado por la oportunidad de financiación disponible. Esto evidencia una cierta incomprensión de los agentes acerca de la filosofía que subyace en un cluster que no puede basar su existencia en la financiación externa sino la capacidad para generar riqueza a partir de la colaboración entre sus propios miembros y de éstos con empresas/organismos externos.

En definitiva, este estudio contribuye a evidenciar las dificultades de evaluación de un instrumento de política en su aplicación práctica, con resultados, en muchas ocasiones intangibles y difíciles de medir (mejora de la cultura colaborativa, incremento de conocimiento, acercamiento a la innovación, etc.). Asimismo se han evidenciado las diferencias entre la fase de planificación y ejecución de las iniciativas de innovación y las características propias del sector turístico que pueden actuar a modo de barreras para el óptimo funcionamiento de un cluster.

Tabla 3

ELEMENTOS DE CONTRASTE TEORIAA-PRÁCTICA EN LAAPLICACIÓN DEL PROGRAMA DE AEIS AL SECTOR TURÍSTICO

\begin{tabular}{ll}
\hline Elementos clave de la política cluster & Aspectos observados en el análisis empírico de las AEIs turísticas \\
\hline & - Dificultad para identificar el ámbito territorial del efecto \\
- Efecto aglomeración derivado de & aglomeración \\
la concentración geográfica de & No se han podido constatar los efectos beneficiosos de la proximidad \\
empresas & geográfica \\
& - Importancia de la proximidad social (vínculos basados en afinidad y \\
& confianza) y la proximidad cognitiva \\
\hline & - Importancia de relaciones preexistentes entre los participantes: \\
& génesis orgánica del cluster \\
- & Importancia del beneficio/utilidad percibidos de la innovación para \\
Cooperación orientada a la & la implicación del sector empresarial. \\
innovación & La cooperación es más efectiva cuando existe un ente de gestión \\
& formal \\
- & Cooperación entre empresas tecnológicas y turísticas en proyectos \\
& turísticos de carácter tecnológico \\
\hline
\end{tabular}




\begin{tabular}{ll}
\hline & - Relaciones interclusters positivas aunque requieren mejor definición \\
& (distribución de la financiación, tareas, etc.). \\
- & Efecto positivo de las sinergias de programas de apoyo a estructuras \\
& cluster a diferentes escalas. \\
- Cooperación orientada a la & Escasa participación de los organismos de investigación y \\
innovación & universidades como entes generadores de conocimiento por \\
& excelencia. \\
- & Escasa tradición colaborativa y predominio del comportamiento \\
& empresarial individual \\
- & Escaso liderazgo del sector empresarial \\
- & Dependencia excesiva del incentivo público como tractor de \\
& iniciativas (subvención total o parcial). \\
- & Surgimiento espontáneo asociado a la oportunidad de subvención \\
\hline Liderazgo del sector privado & Falta de capacidad de absorción del nuevo conocimiento generado \\
& por los proyectos piloto desarrollados \\
- & Escaso nivel de comercialización/implantación masiva de los \\
& proyectos desarrollados. \\
\hline Transferencia de conocimiento &
\end{tabular}

Elaboración propia.

\section{CONCLUSIONES}

La evaluación del Programa de Agrupaciones Empresariales Innovadoras presenta limitaciones compartidas por otros estudios relativos a las AEIs (Aranguren, 2010; Ybarra \& Doménech, 2011) puesto que es difícil medir los efectos de unas políticas que tienen una perspectiva de largo plazo y que, en España, tan sólo tienen una trayectoria de 5 años; donde es difícil establecer relaciones causa-efecto; y los clusters presentan características dispares, en las que no siempre es fácil aislar los efectos del entorno o de otras políticas que inciden en la actividad de las AEIs. La naturaleza relacional del Programa y su reciente puesta en marcha le confieren el carácter propio de un proceso de aprendizaje, cuyo análisis es útil para mantener o reformular las medidas de fomento de las AEIs. Ante estas limitaciones y la naturaleza del Programa, la investigación cualitativa realizada con los gerentes de las AEIs enriquece y complementa los indicadores tradicionales de evaluación utilizados por la administración responsable para la totalidad de sectores participantes (MITYC, 2011a, 2011b).

Sin duda, a la vista de las AEIs constituidas y los proyectos por ellas ejecutados, el Programa ha supuesto un estímulo a la innovación turística bajo parámetros positivos, hasta la fecha escasamente desarrollados: iniciativas guiadas por una reflexión previa en torno al plan estratégico preceptivo; intensificación de las relaciones de colaboración entre los miembros integrantes de las AEIs; puesta en marcha de proyectos de innovación relevantes; colaboración interclusters entre áreas geográficas dispersas para la presentación de proyectos conjuntos; concesión de mayor valor al conocimiento turístico; y mejora de la cultura de la innovación.

Sin embargo, como se ha visto, no es posible hacer únicamente una lectura positiva de la aplicación del Programa. En algunos casos se observan estructuras forzadas ya que los procesos colaborativos no han sido del todo espontáneos y por iniciativa propiamente 
empresarial (bottom-up). En ocasiones, el incentivo a su creación ha sido público o derivado de la oportunidad de obtener financiación pública para el desarrollo de proyectos. Esto ha puesto en evidencia una debilidad estructural del sector turístico, excesivamente atomizado, y poco habituado a ser por sí solo el motor de iniciativas innovadoras colaborativas. Si bien el impulso inicial de la Administración ha sido positivo, queda por determinar cómo seguirá apoyando ésta la continuidad de los clusters creados no sólo en términos de financiación sino en términos de guía, acompañamiento, apoyo en la difusión de las innovaciones creadas, etc., tema objeto de interés, en investigaciones futuras.

En cuanto a su funcionamiento interno, numerosos cluster han demostrado escasa capacidad de consolidación por falta de financiación externa y la existencia de una figura formal (gerente contratado) que orientara el trabajo que, de forma espontánea, debía darse entre los miembros integrantes. Asimismo, el objetivo inherente al cluster de generar innovación a través de proyectos específicos se ha visto condicionado por la escasa financiación, el limitado nivel de participación de las empresas, o la falta de cultura empresarial en torno a la innovación colaborativa o abierta, entre otros factores.

La tipología de AEIs resultante del Programa es muy diversa y abarca situaciones muy diferentes, las cuales determinan el desarrollo de su actividad. La componente territorial de las AEIs, el efecto cluster como sistema localizado de empresas que cooperan y compiten, resulta prácticamente marginal, por lo que el impacto del Programa en la gestión de los destinos desde la perspectiva local ha sido escaso cuando constituye una vía interesante para favorecer procesos de innovación en destinos con una masa crítica de empresas, tanto en el litoral como en áreas urbanas y de interior. Un aspecto que es conveniente revisar por dos motivos fundamentales: orientar los principales destinos turísticos hacia la innovación y favorecer la configuración de AEIs más sólidas en términos de volumen de negocio, relaciones interempresariales y conocimiento acumulado.

Tanto en el plano teórico como empírico, se corrobora que la configuración y el desarrollo de clusters requiere un horizonte temporal considerable. Sin embargo, el Programa está diseñado para que una AEI funcione como un verdadero cluster en 2-3 años, un objetivo demasiado ambicioso, cuyo cumplimiento se agrava con las restricciones presupuestarias y la escasa cohesión de numerosas AEIs que no han tenido continuidad futura. El Programa hubiera requerido una selección más exigente de las AEIs en términos de recursos y capacidades para la innovación, diferenciando claramente el concepto de AEI de una asociación turística convencional, un enfoque más gradual del programa y una mayor asistencia técnica por la Administración turística adaptada a la variabilidad contextual de cada AEI.

Esta variabilidad de contextos también hace necesaria una mayor involucración de las administraciones regionales y locales. El Programa acusa un cierto centralismo que contrasta con la descentralización de las competencias de turismo en España y dificulta la coordinación de iniciativas para promover la innovación en el sector turístico. Resulta incongruente el papel marginal de las Comunidades Autónomas en este Programa cuando otras iniciativas turísticas basadas en la cooperación interadministrativa, han demostrado la oportunidad y validez de este enfoque en el actual marco político-administrativo (los Planes de Excelencia y Dinamización Turística, por ejemplo).

De igual modo, las universidades y centros tecnológicos deberían desempeñar un papel más activo en el Programa para fortalecer la presencia del turismo en el sistema de I+D+i. La 
asociación conocimiento-talento-innovación no puede fortalecerse sin la potenciación de la denominada triple hélice (empresa, administración y centros de investigación) en procesos de innovación como los que trata de impulsar el Programa de AEIs turísticas.

Este Programa contiene elementos de indudable interés derivados, fundamentalmente, de facilitar el acceso a financiación para la innovación sobre bases colaborativas, a diferencia de iniciativas más convencionales orientadas a la modernización y tecnificación de empresas turísticas. Sin embargo, el contexto socioeconómico actual marcado por la crisis económica, que se traduce en ajustes presupuestarios notables y perspectivas empresariales inciertas, y el balance de ejecución de este periodo, hacen aconsejable una reformulación del mismo atendiendo a los factores destacados en el presente artículo. Por último, en el ámbito de la investigación, el estudio del Programa de AEIs en España ha permitido identificar diferentes temas de discusión para investigaciones futuras que contribuirán a ampliar el cuerpo teórico en torno a la innovación y el turismo y a mejorar la eficiencia de las políticas públicas en este ámbito.

\section{BIBLIOGRAFÍA}

ANTON, S. y DURO, J.A. (2010): Innovación turística en España: retos de la política turística, gobernanza de los destinos y desarrollo de sistemas territoriales de innovación, Estudios Turísticos, 185, 7-32.

ARANGUREN, M. (2010): Política clúster del País Vasco: lecciones aprendidas y retos. Revista EAN, 68, 86-99.

ARANGUREN, M., DE LA MAZA, X. DAVIDE, M., \& WILSON, J. (2009): Asociaciones clúster de la CAPV: desempeño y retos. Deusto: Universidad de Deusto.

ARAGÓN, C., ARANGUREN, M.J., ITURRIOZ, C., LARREA, M., OLARTE, F.J. (2009): A new step in cluster policy evaluation. Orkestra Working Paper Series in Territorial Competitiveness, Deusto Foundation, San Sebastian, Spain.

AURIOLES, J., FERNÁNDEZ, M., \& MANZANERA, E. (2008): El distrito turístico. Mediterráneo Económico, 13, 299-325.

BATHELT, H., MALMBERG, A., \& MASKELL, P. (2004): Clusters and knowledge: local buzz, global pipelines and the process of knowledge creation. Progress in Human Geography, 28, 1, 31-56.

BECATTINI, G. (2005): La oruga y la mariposa. Un caso ejemplar de desarrollo en la Italia de los distritos industriales: Prato (1954-1993). Valladolid: Universidad de Valladolid.

BELL, G. (2005). Clusters, networks and firm innovativeness, Strategic Management Journal, 26, 287-295.

BOSCHMA, R. (2005). Proximity and innovation. A critical assessment, Regional Studies, 39:1, 61-74.

BUHALIS, D. (2000): Marketing the competitive destination of the future. Tourism Management, 21, 1, 97-116.

CAMISÓN, C. \& MONFORT, V. (2012): Measuring innovation in tourism from the Schumpeterian and the dynamic-capabilities perspectives, Tourism Management, 33, 776-789.

CARAVACA, I., GONZÁLEZ, G., MÉNDEZ, R. Y SILVA, R. (2002): Innovación y Territorio. Análisis comparado de Sistemas Productivos Locales en Andalucía, Consejería de Economía y Hacienda, Junta de Andalucía, Sevilla. 
COOPER, C. (2006): Knowledge management and tourism. Annals of Tourism Research, 33, $1,47-64$.

CRISTINA, E., FERREIRA, J., \& VITOR, B. (2010). Entrepreneurial Strategies within the Tourism Cluster of Serra da Estrela: Implications for Regional Competitiveness. Advances in Management, 3, 6, 55-65.

DEBBAGE, K., \& IOANNIDES, D. (2004): The cultural turn? Toward a more critical economic geography of tourism. In Lew, A., Hall, M. \& Williams, A. (Eds.), A companion to tourism (pp. 99-109). Oxford: Blackwell.

DENZIN, N. (1970): The research act in sociology. London: Butterworth.

ERKUS, H. (2009): The role of cluster types and firm size in designing the level of network relations: The experience of the Anatalya tourism region. Tourism Management, 30, 589597.

ETZKOWITZ, H, (2003): Innovation in innovation: the Triple Helix of university-industrygovernment relations. Social Science Information, 42, 3, 293-337.

GAROFOLI, G. (1989). Industrial districts: Structure and transformation. Economic Notes, $1,37-54$

GORDEN, R. (1987): Interviewing. Strategy, techniques and tactics. Illinois: Dorsey Press.

PRATS, LL. GUIA, J., \& COMAS, J. (2006): The destination as a local system of innovation: the role of relational networks. In Lazzeretti, L., \& Petrillo, C. (Eds.), Tourism local systems and networking (pp. 57-65). Amsterdam: Elsevier.

HALL, C. M., y WILLIAMS, A. M. (2008): Tourism and innovation. London: Routledge.

HALL, C. M. (2009): Innovation and tourism policy in Australia and New Zealand: never the twain shall meet? Journal of Policy Research in Tourism, Leisure and Events, 1. 1, 2-18.

HERNÁNDEZ, J., PEZZI, A., \& SOY, A. (2010): Clusters y competitividad: el caso de Catalunya (1993-2010). Barcelona, Generalitat de Catalunya.

HJALAGER, A. (2012): Innovation policies for tourism, International Journal of Tourism Policy, vol. 4, no 4, pp. 336-356

HJALAGER, A. (2010): A review of innovation research on tourism. Tourism Management, $31,1-12$

HJALAGER, A. (2000): Tourism destinations and the concept of industrial districts. Tourism and Hospitality Research, 2, 3, 199-213.

HONG, W. (2008): Competitiveness in the Tourism Sector. Taiwan: Physica-Verlag.

HOSPERS. G., SAUTET, F., \& DESROCHERS, P. (2008): Silicon somewhere: is there a need for cluster policy?. In Karlsson, Ch. (Ed.) Handbook of research innovation and clusters, 430-446. Cheltenham: Edwar Elgar

IORDACHE, C., CIOCHINA, I., \& ASANDEI, M. (2010): Clusters. Tourism Activity Increase Competitiveness Support. Theoretical and Applied Economics, 5, 99-112.

JACKSON, J. (2006): Developing Regional Tourism in China: The potencial for activating business clusters in a socialist market economy. Tourism Management, 27, 695-706.

JACKSON, J., \& MURPHY, P. (2002): Tourism destinations as clusters: Analytical experiencies from the New World. Tourism and Hospitality Research, 4, 1, 36-52.

JACOB, M., TINTORÉ, J., AGUILÓ, E., BRAVO, A., \& MULET, J. (2003): Innovation in the tourism sector: results from a pilot study in the Balearic Islands. Tourism Economics, $9,3,279-295$. 
KELLY, I. (2001): Australian Regional Tourism Handbook: Industry Solutions. Gold Coast, Qld: CRC for Sustainable Tourism.

LAZZERETTI, L., \& CAPONE (2006): Identification and analysis of tourist local systems: an application to Italy (1996-2001): In Lazzeretti, L., \& Petrillo, C. (Eds.), Tourism local systems and networking (pp. 26-41). Amsterdam: Elsevier.

LAZZERETTI, L., \& PETRILLO, C. (2006): Tourism local systems and networking. Amsterdam: Elsevier.

MARTIN, R. \& SUNLEY, P. (2003): Deconstructing clusters: chaotic concept or policy panacea? Journal of Economic Geography, 3, 5-35

MEDINA, D., MEDINA, R. \& ZUÑIGA, A. (2013): Tourism and innovation in China and Spain: a review of innovation research on tourism, Tourism Economics, 19, 2, 319-337.

MÉNDEZ, R., SÁNCHEZ, S., ABAD, L. Y GARCÍA, I. (2008): «Dinámicas industriales, innovación y sistema urbano en España: trayectorias de las ciudades intermedias», Boletín de la Asociación de Geógrafos Españoles, 46, 227-260.

MICHAEL, E.J. (2003): Tourism micro-cluster, Tourism Economics, 9, 2, 133-146

MICHAEL, E.J. (2007): Micro-clusters and networks: the growth of tourism. The Netherlands: Elsevier.

MINISTERIO DE INDUSTRIA, TURISMO Y COMERCIO (2011a): El programa AEIs en el marco de las políticas internacionales de apoyo a los clusters. Una valoración. Madrid.

MINISTERIO DE INDUSTRIA, TURISMO Y COMERCIO (2011b): El programa AEIs 2007-2013. Balance actualizado de 5 años de aplicación de la política cluster. Madrid.

MONITOR COMPANY (1991): Ekonomiaz. La ventaja competitiva de Euskadi. Fase I: Identificación del potencial de competitividad (21), 156-209.

MONITOR COMPANY (1992): Els avantatges competitius de Catalunya. Barcelona: Dpto. Economía y Finanzas. Generalitat de Catalunya.

MORGAN, K. (2004). The exaggerated death of geography: learning, proximity and territorial innovation systems, Journal of Economic Geography, 4, 3-21.

NORDIN, S. (2003): Tourism clustering and innovation-paths to economic growth and development. Oestersund, Sweden: European Tourism Research Institute, Mid- Sweden University.

NOVELLI, M., SCHMITZ, B., \& SPENCER, T. (2006): Networks, clusters and innovation intourism: a UK experience. Tourism Management, 27, 1141-1152.

OECD (2005): Oslo Manual: Guidelines for Collecting and Interpreting Innovation Data. Luxemburg (3rd Edition): Statistical Office of the European Communities.

PARRA, E., \& SANTANA, A. (2011): Innovación en modelos organizativos: un análisis a través de los clusters de turismo españoles. Papeles de Economía Española, 128, 254265.

PITTAWAY, L., ROBERTSON, M., MUNIR, K., DENYER, D. AND NEELY, A. (2004), Networking and innovation: a systematic review of the evidence. International Journal of Management Reviews, 5, 137-168.

PORTER, M. (1998). On competition. Harvard Business School Press.

PORTER, M. (1990). The competitive advantage of nations. London: Macmillan.

PORTER, M. (1986). Competition in Global Industries. Boston: Harvard Business School. 
PRATS, L., GUIA, J. \& MOLINA, F. (2008): How tourism destinations evolve: The notion of tourism local innovation system. Tourism and Hospitality Research, 8, 178-191.

RICHARDSON, S., KLEIN, D., \& DOHRENWEND, B. (1965): Interviewing: Its forms and functions. New York: Basic Books.

RITCHIE, J. \& CROUCH, G. (2003): The competitive destination: a sustainable tourism perspective. Wallingdorf: CABI Publishing.

SANTOS, C., ALMEIDA, A. \& TEIXEIRA, A. (2008): Searching for Clusters in Tourism. A Quantitative Methodological Proposal. Oporto University: FEP Working Papers, 1-42.

SCOTT, N., BAGGIO, R. \& COOPER, C. (2008): Network analysis and tourism. From theory to practice. Clevedon: Channel View.

SIMMIE, J. (2008): The contribution of clustering to innovation: from Porter I agglomeration to Porter II export base theories. In Karlsson, Ch. (Ed.), Handbook of research innovation and clusters (pp. 19-32). Cheltenham: Edwar Elgar.

STRAUSS, A., \& CORBIN, J. (1990): Basics of qualitative research: Grounded theory procedures and techniques. Newbury Park: Sage.

SVENSSON, B., NORDIN, S. \& FLAGESTAD, A. (2006): Destination Governance and Contemporary Development Models. In Lazzeretti, L., \& Petrillo, C. (Eds.), Tourism local systems and networking (pp. 83-95). Amsterdam: Elsevier.

SVENSSON, B., NORDIN, S. \& FLAGESTAD, A. (2005): A governance perspective on destination development - Exploring partnerships, clusters and innovation systems. Tourism Review, 60, 2, 32-37.

THE CLUSTER CONSORTIUM (1999): South African tourism collaborative action process. Retrieved April 12, 2013, from The Economic \& Competitiveness Group Web site: http://www.ecgroup.com/documents/South\%20Africa\%20Master.pdf

TRULLÉN, J. y CALLEJÓN, M. (2008): Las agrupaciones de empresas innovadoras, Mediterráneo Económico, 13, 459-478.

UNWTO (2012). Tourism Highlights. 2012 Edition. Madrid: UNWTO.

Weidenfeld, A., Williams, A., \& Butler, R. (2010a): Knowledge transfer and innovation among attractions. Annals of Tourism Research, 37, 3, 604-626.

WEIDENFELD, A., BUTLER, R. W., \& WILLIAMS, A. M. (2010b): Clustering and Compatibility between Tourism Attractions. International Journal of Tourism Research, 12, 1-16.

WEIDENFELD, A., WILLIAMS, A.M, \& BUTLER, R. (2011): Why cluster? Text and subtext in the engagement of tourism development policies with the cluster concept. In D. Dredge \& J.M Jenkins (Eds.), Stories of practice: tourism policy and planning. Ashgate Publishing.

YBARRA, J. \& DOMÉNECH, R. (2011): Las agrupaciones de empresas innovadoras y la política industrial española basada en el territorio. Economía Industrial, 380, 143-152. 
